\title{
EN MEMORIA DE FRANCISCO ROMERO
}

Sumario: 1. La carrera académica. 2. El neoamericanismo. 3. La áporética. 4. El personalismo. 5. La trascendencia. 6. Las concepciones del mundo., 7. La cultura. 8. La teoría del hombre. 9. La jefatura espiritual, 10. Bibliología.

La filosofía iberoamericana está de duelo. No sỏlo ella: la intelectualidad toda de América. Duelo hondo, agobiante, que trata de tomar forma en expresión unánime. Francisco Romero ha muerto. Ha poco; el 7 de octubre del año retropróximo.

Al morir, conviértese Romero en un clásico de la filosofía iberoamericana. Era... y seguirá siendo por algunos años el pensador más leído en estas tierras. Si alguna vez, en $194^{6}$, tuvo que ausentarse de la Universidad Argentina por incompatibilidades de orden político, sus ideas cobraron mayor autoridad, pasada con éxito esta prueba de independencia académica. Ahora, su pensamiento, ya inalterable, vive en el recuerdo como acicate y modelo, y de aquí, de este reino ya no podrá ser desterrado.

\section{La carrera académica ,}

Un hecho, entre otros, confirma su incoercible vocación filosófica: fue Francisco Romero un autodidacta en este ramo del saber. Una vez que terminó el bachillerato ingresó como alumno en el Colegio Militar (hasta 19i2). Aún hubo de consagrarse durante cinco años más a estudios técnicos de ingeniería (hasta 1917). Pero ya en esta época recorría por cuenta propia - y con desusada delectación - la historia toda de la filosofía. De ello tenía noticias Alejandro Korn, profesor a la sazón en la Universidad de Buenos Aires y promotor señero de la filosofía contemporánea en la Argentina.

En 1928 hay un vuelco en la vida de Romero. Ingresa a la docencia como profesor suplente de filosofía en la Universidad de Búenos Aires. Dos años más tarde se retira de la carrera de las armas, al ser nombrado profesor titular en el Instituto del Profesorado en la propia capital de la República. En 1996, año de la muerte de Korn, ocupa el cargo de profesor en la Universidad de La Plata. Ya antes había aceptado, a instancias del mismo Korn, sustituirle en la cátedra y formar parte, en 1929, de la Sociedad Kantiana de Filosofia, la cual, en la Argentina, fue un centro de renovación en no insig. nificante medida (Cfr. Alejandro Korn, 1940; en colaboración).

iNotoria y fructífera labor de Francisco Romero en estos años! Su inicial tarea le hizo ver la importancia de las asociaciones culturales libres en Latinoamérica. Por ello, pronto se asocia como miembro fundador al $\mathrm{Co}$ 
legio Libre de Estudios Superiores. Es ésta una institución, con sede en Buenos Äres, encargada de promover la investigación -creadora en los más altos niveles del saber, y, a manera de obligada secuencia, difundir los hallazgos' logrados. En 1930, por iniciativa de Francisco Romero quedó fundada en este Colegio la cátedra "Alejandro Korn", con la mira de cultivar én grado intensivo - y extensivo- los estudios filosóficos. Dicha cátedra actúa como centro de información e investigación filosóficas y está dotada de una biblioteca dentro de la cual ocupa destacado sitio la bibliografía americana. Muchos trabajos de Francisco Romero, quien desde 1931 laboró en el benemérito Colegiò, han salido de esta cátedra.

Fuera de la cátedra oficial, Romero pudo realizar una actividad docente digna de encomio. En muchos centros de enseñanza fue escuchada su voz, la que, con'frecuencia, despertó vocaciones en unos y afirmó actitudes en otros. Cuando hubo de retirarse de la universidad, ejercía ya el cargo de jefe espiritual de la juventud argentina. Ésta pudo, en efecto, continuar en contacto docente con él no sólo a través de sus publicaciones, sino también en instituciones no vinculadas a lá administración oficial. Más de un centenar de cursos y conferencias acreditan tan devota y fecunda actividad.

Era Romero un excelente escritor. Conceptuoso, ordenado, diáfano, tuvo la aptitud de hacer comprender a los más las ideas filosóficás de los menos. Realizó -el requerimiento de Ortega y Gasset de que "la cortesía del filósofo es la claridad". Acaso sus mocedades filológicas tuvieron :alguna parte en esta su calidad de escritor. Aparte sus libros, Romero' colaboró en importantes revistas de filosofía en lengua española, y no sólo: redactó y publicó artículos en revistas extranjeras como la Philosophy and Phenomenological Research, La Nueva Democracia, The Personalist (de-EE. UU.) Filosofia y Letras y Cuadernos Americanos (de México); Revista Cubana de Filosofia (de Cuba); Revista de Filosofia (de Chile); Universidad de Antioquia e Ideas (de Colombia)... En la Argentina, compuso artículos sobre filosofia, desde 1920, en la revista Nosotros. Más tarde alcanzó merecido prestigio en las revistas: Valoraciones (dirigida por Alejandro Korn), Sintesis, Sur, La Vida Literaria, La Naciön, Espiga, Minerva. La culminación académica en esta suerte de actividades está representada por la publicación dè su revista Realidad, una de las revistas especializadas de mayor vuelo y enjundia en América.

En este orden de quehaceres, precisa recordar la obra renovadora que emprende y realiza como director de la Biblioteca Filosófica de la Editorial 'Losada, de Buenos Aires. No es hipérbole. Romero imprime un nuevo sesgo a la edición de libros filosóficos. Su propósito es múltiple: educar y aleccionar, hacer crítica y conciencia histórica, mostrár y valorar lo americano, promover e investigar. Su programa de publicaciones se propuso y dio a la estampa libros que satisficieron hondas necesidades intelectuales. Los clá- 
sicos, la filosofía actual, pensadores sobresalientes, autores argentinos y americanos, todos tuvieron -aún tienen - cabida en esta Biblioteca, la cual redondea sus nuevos propósitos creando un fichero de filósofos (en donde se da a conocer in nuce la personalidad de los autores) y un archivo, destinado a aprovechar el aporte de críticos y lectores en obsequio del mejoramiento de los textos. .

\section{El neoamericanismo}

Francisco Romero ha sido un americanista en el más castizo de los sentidos. Contribuyó grandemente a la difusión de la filosofía europea en Hispanoamérica, con la idea de preparar el caminó para que aquí, en estas latitudes, surgieran, así fuera a largo plazo, doctrinas originales, bien que vinculadas a la tradición occidental. Él mismo acusa claras influencias; además de Korn (1860-1936), su amigo y maestro, de Ortega y Gasset, Bergson, Croce, Husserl, Dilthey, Köhler, Scheler, Hartmann. Su doctrina de la trascendencia, acaso lo que hay más original en él, es un ejemplo de cómo, ahondando en los rendimientos del pasado inmediato, puédese vitalizar, fecundar y aun engendrar inéditos pensamientos, y, gracias a sus calidades de escritor y de esforzado catedrático, influir en esta tarea americana en pensadores como Risieri Frondizi, Aníbal Sánchez Reulet, Eugenio Pucciarelli, Alfredo Poviña, Juan Adolfo Vázquez...

Romero instruye, en efecto, en un nuevo americanismo. Formula el requerimiento a pensadores americanos de la'creación filosófica; sí, pero de una creación auténtica, genuina, a salvo de todo disfraz vanidoso. La actitud, aun no extraña, de intentar singularizar lo americano a tal extremo de creer en una filosofía americana sui generis, es errónea, estéril, acaso producto de un velado resentimiento. Lo americano es occidental; bien que exhibe características de peculiar naturaleza. En el orden de estas ideas, se adelanta a decir Romero (Cfr. Sobre' la filosofía americana, 1952), que hay en América cierta unidad innegable, y nada mejor para entender lo qué ocurre en un país que tener en cuenta lo que ocurre en los demás. Quien se pronuncie en contra de esto, aduciendo la escasa densidad de nuestras realizaciones filosóficas, ofrecerá un argumento escasamente valedero, en primer lugar, porque buenas, medianas o malas, serán en este plano lo que se va haciendo en estas tierras, $y$, en segundo término, porque la organización de nuestra conciencia filosófica es un hecho de por sí considerable, fueran las que fuesen sus manifestaciones concretas actuales. Que esa conciencia existe, como entidad colectiva, es cosa cierta, y lo confirma la circunstancia de que se hayan planteado ciertas cuestiones que la suponen; por ejemplo, las discusiones sobre la unidad o diversidad de la filosofia en las dos Américas, y las que van definiendo, en el ámbito hispanoamericano, dos tendencias o propensio- 
nes opuestas, una de intención regionalista y otra que apunta al universalismo; discusiones o disidencias fecundas, que contribuirán a que nuestro pensamiento vaya acendrándose y poniéndose en claro sobre sí mismo.

Ya, a decir verdad, Iberoamérica ensaya sús doctrinas. Son, por ahora, gérmenes más que otra cosa. Se podría acaso indicar que nuestra filosofía - parece sentir marcada predilección por las cuestiones atinentes al espíritu, los valores y la libertad, y aún intuir la profunda unidad de estos tres términos, tendiendo a la afirmación del espíritu como la esencia o el ápice de la realidad, y viendo ante todo en la espiritualidad la libre realización del valor. La cuestión o el sentimiento de la libertad está de continuo presente en muchos filósofos de nuestras tierras; ya ocupaba lugar céntrico en el pensamiento de un Vaz Ferreira, de un Deustua, de un Korn, para no citar otros, y parece afirmarse entre los de las nuevas generaciones. Para el hombre americano, la libertad es una experiencia tanto colectiva como individual, pórque las naciones de América se constituyen y nacen mediante àctos de liberación, y porque el individuo tiene ante sí un amplio horizonte geográfico y social abierto a su libre iniciativa. Acaso esta doble experiencia concordante contribuya a que su pensamiento teórico siga tal dirección, no como promoción metafísica de una casual șituación, sino como ocasión favorable para que ante él se revele y descubra la última esencia o sentido de la realidad.

La vocación filosófica de Iberoamérica es notoria, aunque sólọ ahora empieza a tomar conciencia de sí; numerosas expresiones de ella surgen independientemente unas de otras por todo el vasto territorio continental e insular, mostrando con la espontaneidad de su aparición la autenticidad del, interés y su' íntima necésidad.

\section{La aporética}

Al hablar de la filosofia de Francisco Romero, precisa considerar a ésta en sus 'etapas sucesivas, en su desarrollo. Exposición génética, histórica. Es el de Romero en efecto, un pensamiento que se ha ido integrando al correr de los años. Y ló que és más significativo: el filósofo argentino tuvo siempre clara conciencia de este explicable y plausible tránsito del saber. Quizás por ello muy pronto se vincula a la idea dé Nicolai Hartmann en torno del estilo aporético de filosofar. Para Romero ya ha pasado la época de los grandes sistemas. La filosofía moderna, dice, no acepta' ningún sistema predeterminado sobre la realidad. Libre de prejuicios encara los problemas. Sólo la voluntad de verdad debe mantener en vilo al filósofo. Tratar de resolver los enigmas todos del universo partiendo de un solo concepto, sea el de la materia (materialismo), el del espírítu (espiritualismo), o el de la idea (idealismo), es cerrar los ojos a lo que se ofrece a la reflexión filosó- 
fica. Los sistemas aparecen y desaparecen. "El tiempo inexorable los deposita a todos en los archivos de la historia de la filosofía, y lo que una vez pretendió ser asunto de vida se trueca en tema de mera curiosidad escolar... El destino del pensamiento que afronta problemas es distinto, no obstante. Este tipo de pensamiento forcejea con los enigmas, combate las dificultades, lucha con las antinomias, o con lo que Hartmann, recordando a Aristóteles, llama aporia, que etimológicamente significa sin camino. La empresa contradictoria del pensamiento consistirá por lo tanto en encontrar camino donde no lo hay." (Cfr. "Un filósofo de la Problematicidad", 1934.)

El pensador argentino expresa su viva experiencia de este aporético estilo de filosofar en un escepticismo metódico, en aquella actitud filosófica, discreta, escrupulosa, que duda y coteja antes de formular un meditado dictamen. "Mi oficio, dice, no es dogmatizar ni acostumbro dar por seguridades mis probabilidades. No pienso nunca renunciar a un derecho que es para mí uno de los más indudables del intelectual, y que no excluye ciertas incomodidades, el derecho a la duda."

Ahora bien, esta duda metódica, que no sistemática, no lo lleva al relativismo filosófico. Su concepción del mundo y de la vida es un enfático subjetivismo. La verdad es, para Romero, la conformidad de un conocimiento con la situación objetiva que enuncia. Lo opuesto a la verdad es el error. "Un conocimiento es fatalmente o verdadero o falso: no hay grados, no existen términos intermedios. No hay, por tanto, verdades relativas." (Cfr. "Teoría y Práctica de la Verdad, la Claridad y la Precisión", 1939.)

Pero el conocimiento es una tarea ardua, que así en la ciencia particular como en la filosofía requiere "un saber crítico y reflexivo". La verdad tiene existencia autónoma por sí. El conocimiento y posesión de la ver: dad, la certeza depende de que la situación sobre la cual se enuncia el juicio sea o no accesible. Hay situaciones inalcanzables de hecho, por ahora al menos: no podemos, por ejemplo, ir al centro del Sol y observar qué hay allí. Hay situaciones incomprobables por razones de principio; por ejemplo, no podemos conocer la dimensión de ningún cuerpo, la dimensión estricta, se entiende. La física actual sostiene que la observación de la realidad natural se detiene ante límites infranqueables, que la misma aproximación no es indefinida. (Cfr. Lógica y Nociones de Teoría del Conocimiento, 1948.)

Los más altos rendimientos del saber los alcanza la actitud crítica y reflexiva del hombre, pero en esta manera de captar la realidad, alienta un factor de saber espontáneo, vital. "El saber crítico parte de este supuesto: que el saber seguro y válido no es una espontaneidad, sino una disciplina. De aquí su nota esencial: es saber metódico desde el principio al fin, saber traspasado de un imperativo de autocontrol, de autoconciencia: es saber que se vigila y se sabe a sí mismo, saber saturado de desconfianza y de reservas mentales. Lo primero es eliminar todo elemento extrateórico, todo lo ajeno 
a la esencia misma del saber; lo segundo, procurar que la teoreticidad funcione sin desvios ni tropiezos. El método lo define y lo gobierna, lo flanquea por todas partes y de muchos modos."

\section{El personalismo}

Atento a este tratamiento aporético de filosofar, ya en 1935, encara el autor el problema del hombre. Desde luego le preocupa el tema de la persona humana.

Romero comienza por situar históricamente el problema del espíritu. Parece ser Averroes, en una de sus interpretaciones de un pasaje de Aristóteles, el antecedente directo. Pero, desde Anaxágoras y Sócrates comienza el. drama dialéctico por demostrar la existencia y autonomía del espíritu.

Para describir la esencia de la persona, conviene diferenciar previamente la psiqué del espíritu, pues aluden a dos diversas regiones de la realidad. Al paso que la psiqué constituye esa forma de la realidad proyectada a lo contingente y subjetivo, a lo que satisface las apetencias naturales del hombre, es el espíritu aquel costado de nuestro ser, siempre vuelto hacia la objetividad, esto es, al ser en sí de las cosas, a su recóndita intimidad, al par que aquellos otros modos de objetividad que se llaman valores (belleza, justicia, santidad, etc.).

La persona se identifica, ontológicamente hablando, con el espíritu. "La persona es el individuo espiritual. No es sustancia, no es un ente del que los actos sean la manifestación o la consecuencia; es actividàd, actualidad pura. La persona no es sino el conjunto de los actos espirituales en cada sujeto, pero este conjunto es rigurosamente unitario, de manera que la persona se nos manifiesta al mismo tiempo como un complejo de actitudes espirituales, y como el centro ideal del cual estas actitudes irradian...

"La persona se instalá o se constituye sobre el individuo psíquico como una instancia superior y heterogénea. Su función natural respecto al individuo psicofísico es la de comando. Pero esto no quiere decir que ejerza esta función en todo momento y en cada circunstancia. Unas veces, la llama del espíritu brilla apenas; otras alumbra sin dar calor; otras se torna incendio." (Cír. Filosofía de la Persona, 1935.) "Individuo y persona son dimensiones por lo general opuestas, en guerra, constante. El triunfo es de uno "u otra, según los casos. Muchas cuestiones plantea este antagonismo, y entre ellas una de importancia extraordinaria para el porvenir de nuestra especie: la de si siempre se mantendrá la oposición tal como ahora la comprobamos, o habrá conciliación o acuerdo entre los dos adversarios. El conflicto entre individuo y persona _deriva de la vasta contraposición entre vida y espíritu, discutida repetidamente en la filosofía actual."

Muchos filósofos (Nietzsche, Klages) rompen lanzas por la vida; otros 
(Scheler, Hartmann), por el espíritu, si bien con circunspección crítica estos últimos.

Es el hombre un ente múltiple. En la marcha de las formas inferiores a las superiores se nos presenta como una progresiva unificación, como paulatina estructuración concentrạdora. El hombre, aun como individuo psicofísico, es ya cierta unidad, pero ésta se advierte en la persona en medida mucho más considerable. La persona es efectivamente unidad de coherencia, de consecuencia; unidad como propósito y designio. La unidad es conexión estricta y referencia a un centro. La persona es autoposesión, autodominio, imperio del centro ideal" con el que, en cierto modo, la hemos identificado. $Y$ de esta unidad efectiva y anhelada derivan, como dos exigencias o como dos consecuencias, lo que llamamos "el deber de conciencia y el deber de conducta." El deber de conciencia, el "conócete a ti mismo" del oráculo délfico, es el darse cuenta del designio humano, en cuanto espíritu, pero semejante saber trae consigo el conocimiento de las limitaciones humanas, de lo insignificante que se conoce frente al ideal del absoluto conocimiento; en otras palabras, la conciencia del no saber es un estímulo para la conquista de nuevos y más profundos conocimientos. Al saberse que no se sabe esto o aquello, puede y debe el espiritu afanarse por conocerlo. El deber de conducta se enlaza estrechamente con el deber de conciencia. E1 deber de conciencia nos manda que nos poséamos intelectivamente, que seamos plenamente conscientes de nosotros mismos; ya que hay que extender -este mandato de autoconciencia hasta el de conciencia universal. El deber de conducta nos impone obrar como personas, es decir, desde el centro espiritual. Nos ordena, pues, ante todo, poseernos en la acción, de manera que cada acto nuestro sea "nuestro" en sentido último y radical. Y ello supone impedir a los impulsos que se manifiesten por su cuenta, sin orden ni norma; importa suprimir toda reacción espontánea y periférica $o$, más bien, subordinarlas con el máximo rigor al gobierno del núcleo personal.

\section{La trascendencia}

La vida humana es, pues, compleja; está formada por variados estratos, uno de los cuales, el espíritu, la lleva a las instancias superiores de la existencia (Scheler). Esta aptitud de salir de sí, de trascender, es el nervio motor de la persona. "La persona funciona como un haz de movimientos trascendentes; es pura trascendencia. Su ser es trascender. Trasciende hacia las cosas en el conocimiento, en la delectación estética; trásciende hacia los valores. Trasciende especialmente hacia las demás personas, porque así como al individuo le es consustancial la negación de los demás individuos, pertenece a la esencia de la persona afirmar las otras unidades personales. La religiosidad personal es igualmente un puro trascender hacia Dios, mien- 
tras que la religiosidad del individuo es un mero afán de conciliarse los poderes sobrenaturales, un ensayo de introducirlos en la órbita de sus intereses, de inmanentizarlos." (Cfr. "Persona y Trascendencia", 1937.)

La conciencia del tiempo, la temporalidad e historicidad humanas, es posible por obra y gracia de la trascendencia. El hombre, como quiere Ortega y Gasset, se caracteriza por adelantar su destino a manera de un proyecto de vida; pero ello mismo es factible porque la raíz del ser es la trascendencia. "Ser es trascender" (Cfr. Programas de una Filosofia, 1941).

Hay más: los propios valores, estas instancias ideales que configuran la vida y le confieren sentido, son en definitiva maneras de trascender. Ya se ha dicho: el acto espiritual, vuelto hacia los valores, se agota en su intención trascendente. El espiritu vive en actos y por actos de trascendencia. Un acto de conocimiento, por ejemplo, será espiritual si se ciñe a su objeto y trata nada más que de aprehenderlo, si mantiene limpia su teoreticidad, si es trascendencia pura.

En el dominio de los valores morales la trascendencia se ofrece asimismo de manera reconocida. Es esencial a ellos el trascender. Ya la palabra "altruismo" expresa ese tránsito del sujeto à lo que no es él, la trascendencia de cada centro personal a los centros ajenos. Toda auténtica doctrina ética no es sino teorización de una comprobación inmediata, de la experiencia íntima del primer axiomá moral, que manda obrar desde el punto de vista de la comunidad ideal de las personas, y no desde el punto de vista del sujeto en cuanto individuo singular; también es una intuición primaria y común la de que no hay más pecado en ética estricta que el egoísmo, esto es, el centrar la acción en el sujeto singular y referirla a él sólo, el obrar en el sentido de la inmanencia.

¡Y qué decir de los valores estéticos, que, con razón, suelen asimilarse al concepto de desinterés! Creación y contemplación estéticas por igual son actos de pura trascendencia. Ésta, añade Romero, es total en los actos espirituales, en los actos superiores denominados vulgarmente "desinteresados" (tal desinterés es precisamente la ausencia de intención inmanentizadora), y estos actos, a'su vez, son los que encarnan el valor, como por otra parte lo reconoce unánimemente la experiencia común. "Quedaría por examinar en este punto si el valor recae sólo sobre los actos trascendentes personales, o si se adjunta también a cualquier dosis de trascendencia que ocurra en los entes. Desde luego, aunque la respuesta fúera desfavorable para el segundo término de la alternativa, no es dudoso que una singular dignidad ha de admitirse en el trascender no espiritual (físico, orgánico, psíquico), en cuanto ímpetu que al final desemboca y se resuelve en la suma validez, acaso por una intima necesidad y.como su natural punto de llegada. En suma: la unidad de ser y valor se nos ofrece como identidad del principio ontológico esencial y de aquello que determina y recibe el valor; manteniéndose, em- 
pero, la distinción entre las dos caras del todo, la faz entitativa y la faz valiosa, lo que es y su validez. La unificación sucede sobre todo en el espíritu, instancia en que la trascendencia, libre de cualquier traba, se afirma omnímoda." (Cfr. Trascendencia y Valor, 1942.)

\section{Las concepciones del mundo}

Un tema predilecto de Romero fue el relativo a la esencia y sentido de la cultura humana. Su inquietud sostenida por la idea del valor exhibe ya esta preferencia, pero, de cierto, su preocupación, su gran preocupación por el problema de la concepción del mundo, lo sitúa en el centro de aquella cuestión.

Parece ser que sus estudios sobre Guillermo Dilthey le despertaron el interés por la cosa. Ya en 1932, quiere hacerse claro el problema y la historia de este problema. E1 tema de la concepción del mundo es viejo de siglos, repite una vez y otra; pero por nutridos que sean los materiales anteriores acerca de este problema, puede nuestra época reivindicarlo para sí, porque una cosa es la mera aparición del asunto y otra muy distinta la conciencia y la clara idea del problema. (Cfr. Vieja y Nueva Concepción de la Realidad, 1932.)

¿Qué es, en esencia, la realidad? ¿Qué el mundo? ¿Qué lugar ocupa el hombre dentro del universo? He aqui preguntas que ya en 1932 se formuló Romero, llevado por el incontenido afán de hacerse claro el concepto de existencia. El problema, en todas sus resonancias, es el problema de la concepción del mundo y de la vida.

La filosofía - y la ciencia - ha dado diferentes respuestas al tema, a lo largo de la historia. Mecanicismo, atomismo, asociacionismo, evolucionismo... son nombres que delatan heterogéneas maneras de concebir la realidad.

Pasando revista a los antecedentes, aún en parte vivos, de la manera de entender mundo y vida, Romero ve en el mecanicismo de los Tiempos Modernos una respuesta que ha hecho época en la historia. El vigoroso sostén, o apoyo de ella lo fue y es el racionalismo filosófico. "Desde el Renacimiento hasta fines del siglo xviri, más allá de toda particular teoría, hay una concepción total o teoría-madre, el Racionálismo de Descartes y Leibniz, è sistema de la razón estricta, que domina imperiosamente y da el tono a toda la Edad Moderna. Acaso sea Guillermo Dilthey el hombre a quien debemos las indicaciones más profundas para comprender el espíritu y el sentido de una época que ya comienza a destacarse en perspectiva a nuestra espalda, con una unidad imponente y con sus contornos perfectamente acusados. La física de Galileo y Newton es la transcripción de ese sistema en lenguaje fisico. La psicología de Hume es la versión del mismo sistema en idioma psicológico." 
La influencia de la psicología de Hume ha sido enorme. Contra cualquier otra concepción de lo anímico, párecía haber llegado a una interpretación rigurosamente cientifica que permitiría establecer sucesivamente todas las leyes del acontecer psíquico, casi con la seguridad con que- se establecían las leyes de la realidad física. Esta psicología es la que llega en el siglo xIx hasta J. Stuart Mill y hasta Taine.

Viejas concepciones de la realidad. En ellas todo se quiere explicar de manera analítica. En los cuerpos se ven masas de moléculas y átomos. Lat vida psíquica se explica mediantẻ asociación de sensaciones, y percepciones. La doctrina de la evolución enseñarque todo cambio es el tránsito de lo relativamente simple a lo relativamente complejo. Pero el ticmpo pasa, y, hoy, en nuestro tiempo, se oye una palabra nueva que está sustituyendo las viejas concepciones de la realidad. Es la teoria de la estructura, de la forma (Gestalt, en lengua alemana).

La nueva idea significa un radical cambio de método. El punto de partida es una concepción totalizadora, estructural, de lo real; de ahi se desciende a los elementos, los cuales adquieren un nuevo sentido en tanto se les conoce y determina en función del todo. En psicología, por ejemplo, hay que fijar, ante todo, qué es la experiencia humana total, personal, en conjunto, y sólo a partir de ahí ver el modo de explicar los elementos de que consta. En la filosofía de la cultura, a su turno, es preciso comprender los tipos de culturas en sus estructuras globales antes de proceder a toda consideración anạlítica.

Los espíritus más avisados de nuestro tiempo se hallan grandemente preocupados por una nueva concepción de la realidad. Tras Dilthey $-\mathrm{y}$ bajo el signo de Dilthey - forman en el movimiento M. Scheler, C. Jaspers, A. Vierkandt, K. Koffka, J. Leisegang, W. Köhler, M. Wertheimer. . Hay más: en el idealismo de Schelling y Hegel se advierten ya concepoiones estructurales. En la actualidad, "concluye Romerò, concepciones de índole totalizadora - o estructural sustituyen por todas partes a las nociones en última instancia atomísticas e individualistas del sistema, hoy agotado y caduco, del gran racionalismo europeo, el sistema de la razón abstracta - dentro del cual se òdena la concepción mecánica de la realidad física, la psicología de Hume a Wundt, el derecho natural que reemplaza al derecho divino y culmina en el liberalismo del siglo pasado, la gramática habitual contra la cual polemiza Vossler... y tantas otras parciales interpretaciones de segmentos del mundo y de la vida.

La filosofía actual tiene ante sí, por ello, graves cuestiones: ¿Qué es la estructura como categoría? ¿Cómo funciona ésta? ¿Cuántos tipos de estructura cabe señalar? Preguntas difíciles, arduas. 


\section{La cultura}

Como ya se dijo, entre las realidades más importantes que han de comprenderse estructuralmente, hállase la cultura humana. Para Romero, la cultura es una creación humana. La cultura, dice, es el conjunto de los productos, actos y procesos específicamente humanos. En cuanto cultura objetiva, consiste en un especial mundo de objetos, en un complejo de realidades que, producidas por el hombre, componen a su alrededor un medio o ambiente conforme a su indole, tendencias y necesidades. La sociedad, el derecho y el Estado, la religión, el lenguaje, la ciencia y la filosofía, las artes, las costumbres, la técnica son objetividades, estructuras de muy definidos y sólidos contornos, que cada uno de nosotros encuentra como preexistentes, como un peculiar orden de "cosas", con cuya existencia y condiciones debe contar en su vida; precisamente nuestra vida consiste en eso: en contar en muy diversas actitudes con esas realidades y en dirigir nuestra acción entre ellas, ya que hasta nuestro trato con lo que no es cultura - los demás hombres, la naturaleza, etc.- ocurre, sin falta, en virtud de una mediación cultural.

La cultura es un expediente de seguridad. 'Gracias a ella el hombre encuentra los caminos de su existencia. Imaginad lo que nos suministra la ciencia transformada en técnica. Y esto, sobre todo, porque los productos culturales son entidades sometidas a un devenir continuo, bien por ellas mismas y en la singularidad de cada una, como la sociedad y el lenguaje, siempre en trance de mutación, bien en cuanto cada particular instancia, en sí conclusa y cerrada, se incluye en una línea de transformación .o acumulación, como las creaciones del arte o las doctrinas científicas, que se suceden y eslabonan, respectivamente, en el campo de la experiencia estética y teórica de una cultura, y, más allá de ella, de la humanidad. La cultura es, pues, realidad histórica.

El espíritu, la persona, dice Romero confirmando de nueva manera: su. doctrina, es impensable sin sus creaciones objetivas. No es sólo una frase. El alma humana no es anterior a la cultura y, lo que es más decisivo, no puede apartarse de ella. Cada nueva época significa una nueva alma, bien que una nueva alma que se va constituyendo sobre el legado cultural 'del pasado creado por otras almas y que, con su aporte a la humanidad, permiten el crecimiento de ésta. La antropología filosófica ha de apartarse de la vieja idea sustancialista del hombre. Éste no ha sido hecho de una vez por todas; es historia, historicidad. Dentro de la tesis de Ortega y Gasset, cabe decir que el hombre no tiene una consistencia rígida, acabada, sino que se resuelve en un mero devenir, tesis que niega de antemano las notas de ser que podrían desprenderse de las constantes de ese devenir mismo, ya que no es un puro acaso, y descuida también la cuestión de la fuente o principio del 
específico devenir humano. "Lá psicologia, la sociología, la teoría de la cultura recortan sus respectivos recintos con una autonomia que no pasa de ser relativa; no deben hacernos olvidar que es el hombre quien se comporta sociológica ý culturalmente, y que no es tal hombre fuera de los respectos sociales y culturales. La certidumbre de que el ente humano se constituye y organiza a través de su vida cultural, no se opone a la existencia en él de un principio que posibilita la vida cultural misma, principio exclusivo suyo como le es exclusiva la cultura; principio que sólo en la vida cultural se actualiza." (Cfr. El Hombre y la Cultura, 1950.)

\section{La teoria del hombre}

En 1952, Francisco Romero tuvo el acierto de presentar en unidad de pensamiento su cabal doctrina del hombre. Apareció su libro intitulado Teoria del Hombre, que, una vez leido, fue objeto de un vivo reconocimiento por los filósofos y círculos filosóficos más importantes de América. EI libro representa, de cierto, la culminación de cuanto había explorado el autor acerca de la filosofía, el hombre y la cultura, en los últimos años" (Cfr. Papeles para una Filosofia, 1945; Filosofias de Ayer y de Hoy, 1947; Filósofos y Problemas, 1947; Ideas y Figuras, 1949), afinando, superando conceptos anteriores.

La Teoría del Hombre tiene el designio de ser sólo una antropología filosófica; pero su autor sitúa la doctrina dentro de una concepción filosófica total, ofreciéndonos así una visión completa de su pensamiento. La obra consta de tres partes. La primera lleva el nombre de "La Intencionalidad" y se ocupa de la conciencia, de la comunidad humana, de la cultura y del yo y el mundo. La sègunda, "El Espíritu", suministra un concepto general de esta esencial idea, de su peculiaridad y significación y de su trato con los valores. La tercera parte se intitula "El hombre". En ella nos brinda los resultados de su meditada especulación, hablando de la dualidad humana, de su enmascaramiento, justificación y conciencia de sí mismo; en fin, de su sociabilidad, historicidad y sentido.

La intencionalidad, esto es, la referencia del sujeto a un ser trascen: dente a él, constituye una característica primaria del hombre. "La trascendencia aparece aquí iluminada por la intencionalidad (Husserl), pero permanece como piedra angular de la doctrina. Intencionalidad y trascendencia, a su turno, operan en un mundo de objetividades. El hombre es un sujeto capaz de objetivar su mundo, y, por ello, de juzgarlo, conociendo y valorando. El término "espíritu" designa esta esencia y calidad humana. El espíritu queda caracterizado como: a) capacidad objetivadora (universalidad); b) libertad (como evasión del determinismo animal); c) historia (como conciencia de pasado y futuro); d) voluntad de valores (dentro de una cul- 
tura) y e) absoluta trascendencia. Estas características, empero, adquieren peculiares rasgos en los diversos pueblos y culturas.

Para Romero, las mayores culturas han sido: la de la India, la de China y la occidental. "Desde el punto de vista del sentido de la vida, cada una de estas tres culturas proporciona una finalidad adecuada para que, mediante su tácita o expresa adhesión a ella, el individuo sienta cumplido su destino. Pero de estos tres grandiosos esquemas, sólo el occidental incluye un elemento que es capital para el hombre, según lo que se ha venido diciendo: la historicidad. La cultura índica es intemporalista; desvaloriza y niega el tiempo. La cultura china es "eternista"; detiene el tiempo, lo paraliza al poner todo presente a la sombra del pasado, al supeditar los hombres vivientes a los antepasados. La cultura de Occidente, en cambio, cuenta con el tiempo en cuanto sucesividad palpitante, lo tiene por indispensable aliado en su propósito de realizar históricamente los requerimientos del espíritu.".

Otra diferencia entre el hombre de Oriente y el occidental reside en el grado, por decirlo así, como ejercen su capacidad de juicio. Al paso que aquél disminuye, anulándolo a veces, el privilegio de juzgar, éste se afirma en la vida como persona mediante la voluntad de saber. El hombre cuando surge como sujeto, cuando confiere objetividad al mundo mediante el juicio; al asumir la postura espiritual, consecuencia suprema, como hemos visto, de la actitud objetivante, agrega a los juicios de objetivación y a los de valoración intencional, otros juicios valorantes, en función del espíritu. El occidental se ha decidido por un destino más duro, pero también más digno, grato y satisfactorio, que el elegido por los hombres de las grandes culturas de Oriente; ha resuelto no renunciar al juicio. $\mathrm{Ha}$ hecho íntimamente suyo el principio que está en la raíz y en la fuente de lo humano, y abrazado a él se proyecta, invicto entre sus innumerables derrotas, hacia las lejanías del porvenir.

Entre los hombres de una misma cultura; más: de un mismo pueblo; aún más: de un mismo grupo, empero, acúsanse diferencias notables. La explicación de ello radica en las diferentes calidades humanas. ¡Qué duda cabe! Un hecho de importancia que lleva a justipreciar la historia y la sociedad es, entre otros, el de la existencia de élites y masas.

\section{La jefatura espiritual}

En una sociedad, de cierto, unos ejercen el mando, la autoridad; otros, obedecen. La relación "mando-obediencia" es, como de suyo se comprende, una de las esenciales formas de la sociedad. No se concibe vínculo colectivo sin este régimen de subordinación.

La subordinación social, por otra parte, asume muchas y diversas for- 
mas. Hay, sí, un mando en política. De fijo, el tema del mando en toda su amplitud, deriva de aquí. Pero al lado de la autoridad política, existen en la vida social otros especímenes de mando, diríase, de poder, de potestad. La Iglesia requiere de una estructura jerárquica, y el feligrés acata mandamientos de diverso tipo. Hay círculos científicos y filosóficos con tareas que exigen actos de subordinación. En la producción artística se habla, con acierto, de rangos y calidades. Pervadiendo todas estas formas de potestad, figura la llamada-opinión pública, mayormente vinculada a la vida política, pero que deja sentir su influjo, para bien o para mal, en las otras vertientes de là existencia humanà.

El mando, por otra parte, se ejerce de diversa manera y en diversos grados. Una persona puede ser un hombre de mando en un sector de la cultura, tal vez en el arte, y ser un súbdito en la vida réligiosa. Dentro de una misma actividad humana un hombre puede tener mayor mando que otro. Los heterogéneos talentos humanos y la creciente complejidad social explican este singular hecho.

Justo: esta diversidad y tipos de "mando" plantea a la antropología filosófica y a la sociología difíciles problemas. Cabe desde luego distinguir entre jefes y modelos. Ante todo, el jefe actúa sobre el grupo de prosélitos con voluntad de mando. Éstos y aquél se conocen entre sí. El súbdito sabe a quien obedece; el jefe tiene conciencia del conglomerado de hombres sobre el cual obra. El jefe, como dice Scheler, tiene que "saber" que es jefe y tiene que "querer" ser jefe. Otra cosa es el modelo. Éste es un paradigma, un prototipo de vida. Suele el hombre-modelo no saber que es modelo, acaso ni querer ser modelo. Es, por ello; que la relación entre modelo e imitador nó requiére la presencia real, bien que suele producirse. En cambio, puede ser modelo para una persona que ha vivido en pasadas épocas.

Sociológicamente considerado, el mando es un hecho neutro, indiferente de toda valoración. Mas cabe -y debe- considerarse el mando a la luz de un juicio de valor. Entonces la reflexión queda ubicada en los dominios de la política filosófica y de la filosofía social. ¿Qué condiciones han de concurrir en un acto de mando para que éste responda a las exigencias de una elevación de la vida humana? ¿Qué es, en suma, un mando calificado?

Francisco Romero llama a esta especie calificada de mando, la jefatura espiritual. Para ilustrar su doctrina, busca el autor en Ortega y Gasset los rasgos que configuran la personalidad de un jefe espiritual (Cfr. Ortega y Gasset y el problema de la Jefatura espiritual, Buenos Aires, 1960).

Un jefe espiritual ha de ser partícipe de reconocida autoridad intelectual, pues ésta implica, por necesidad, energía y acción. El jefe manda en tánto su pensamiento opera, influye de significativa manera. Por ello, su mando tiene un alcance dentro del cual queda ubicado el circulo subordinado. 
Ahora bien, estos rasgos se comprenden en su radical facticidad por otra calidad inseparable del jefe espiritual. La jefatura espiritual lleva invivita una actitud renovadora. El jefe espiritual es siempre un pionero. No pasa de ser uno de tantos jefes quien realiza un programa de acción dentro de la trillada senda de la práctica establecida, de las formas de vida en uso. La jefatura espiritual, cualquiera que sea el sector de la cultura en donde actúe, no es sólo eco del pasado. Supera costumbres, hábitos, formas de existencia tradicionales.

Francisco Romero ha sido un ejemplo vivo de jefe espiritual. Su doctrina sobre este tema ha sido en buena parte una expresión de su personalidad en la última década de su vida. No sólo en la Argentina; en Latinoamérica toda fue un jefe espiritual. Las distinciones académicas y los reiterados homenajes de que fue objeto desde 1940 son testimonio de tan alto merecimiento.

En la Argentina, Romero toma esta jefatura pocos años después de la muerte de Korn (Cfr. Alejandro Korn, Filósofo de la Libertad, 1956). A este pensador estuvo vinculado, de cierto, en la tarea de la renovación de los estudios filosóficos. Primero, a su lado, combate el positivismo; después -y de señalada manera- se entrega a la fecunda obra de sustituir áquella doctrina, a la cual reconoció siempre su importancia en la organización de la vida pública argentina. En la filosofía argentina renovada Romero es el continuador de Korn (1860-1936) y de Coriolano Alberini (1886-1960). (Este último, como se sabe, fue el primero que enseñó en Argentina la filosofía de Bergson, de Boutroux, de Meyerson, de Croce, de Gentile...) Gracias a Romero, en fin, la filosofía y, en general, las humanidades se han institucionalizado. De sus lecciones en cátedra surgieron a su tiempo discípulos aventajados que han podido fundar no sólo nuevas cátedras de filosofia, sino también centros importantes de enseñanza.

\section{Bibliologia}

Es explicable. La obra escrita de un pensador como Francisco Romero ha sido - seguirá siendo- materia de ponderación, de análisis y de crítica. Ya en 1942, el norteamericano Edgar Sheffield Brightman hizo notar la importancia de Romero en los países de habla inglesa. Escribió en ese año el artículo "La Filosofía Contemporánea de Francisco Romero", en la revista Philosophy and Phenomenological Research; en 1943, en la misma revis. ta, "Structure and Trascendence of Thought of F. R.". John H. Hershey, por su parte, en The Journal of Liberal Religion, el estudio intitulado "The Philosophy of Francisco Romero", 1943.

Ya desde 1940, había comenzado, en lengua española, la bibliología sobre él. Cabe mencionar, entre muchos, muchísimos estudios: Cayetano Be- 
tancur: "Tres estudios de Romero" " (Revista de la Universidad Católica Boliviana, Medellín, Colombia, 1940); "El problema de la iniciación filosófica: Diảlogo con Francisco Romero"' (Revista Nacional de Cultura, Caracas, nov.-dic.); Francisco Larroyo: Exposición y crítica del personalismo espiritualista: misiva a Francisco Romero (un libro, i941); 'Luis E. Nieto Arteta: "La filosofía de Francisco Romero" (Revista de la Universidad de Antioquia, Medellín, Colombia, oct.-nov." 1942); Marcos Victoria: "Francisco Romero, un civilizador" (Argentina Libre, $3^{\circ}$ de abril); Risieri Frondizi: "Tendencies in Contemporary Latin American Philosophy" (International Intellectual Interchange, The University of Texas); José Gaos: Antologia del pensamiento de lengua española (México), 1945; sin firma: "Francisco' Romero visto por Recaséns" (en El Atlántico, miércoles 14 de marzo), 1945; idẹm: "Hay que saber quién es quién" (comentario sobre Francisco Romero, Paul Eluard y Antonio Robles, en Critica, Buenos Aires, 3 de febrero); Norberto Rodríguez Bustamante: "Francisco Romero y Papeles para una filosofía" (Cuadernos Americanos, México, V. 3), 1946; Juan. Adolfo Vázquez: "Francisco Romero: Filosofías de ayer y de hoy" (Realidad, Buenos Aires); E. Ferreira da Silva: "A filosofia de Francisco Romero" (Ensaios Filosoficos, "Sao Paulo), 1948; A. Sánchez Reulet: La Filosofía latinoamericana contemporánea (Publicaciones de la Unión. Panamericana, Washington, pp. 321 323), 1949; Humberto Piñera Llera: "Ideas y Figuras" (Nota en Revista Cubana de Filosofia, La Habana, 1. 6), 1950; Humberto Piñera Llera, Vida y obra de Francisco Romero, 1951; José. Ferrater Mora, Francisco Romero, Un Estilo de Filosofar, 1951; Angélica Mendoza; Notas sobre.la. Filosofia de Francisco Romero, 1951; R. Frondizi, "La Těoría del Hombre de Francisco Romero (Fil. y Letras; México), 1953; José Gaos "La Teoría del Hombre de F. R.", Diánoia, 1956 .

El nombre de Francisco Romero figura ya como ficha bibliográfica en importantes enciclopedias. En diccionarios especializados aparece: Diccionario de Filosofia, de José Ferrater Mora; The Dictionary of Philosophy, de Dagobert D. Runes; Enciclopedia filosófica, del Centro di Studi Filosofici di Gallarate.

Francisco Larroyo 